\title{
Pathways to Violence: \\ Dynamics for the Continuation of Large-scale Conflict
}

\author{
Hrag Balian' and Peter Bearman²
}

\begin{abstract}
This article identifies why large-scale multisided civil conflict lasts for so long. The simple answer is that groups engaged in such conflicts have opportunities to achieve coveted ends like dominance and/or revenge by killing members of other groups. We focus on killing events and their temporal ordering rather than on rates. From this perspective, we identify how purely endogenous dynamics lead to conflict continuity and more unusually, conflict failure, or peace. The empirical case we consider is the Northern Ireland "Troubles," |969-200|.
\end{abstract}

\section{Keywords}

events, networks, continuity, conflict

\section{INTRODUCTION}

On March 10, 1971, three Irish Republican Army (IRA) men walked into a Belfast bar and started drinking with a few other guys who turned out to be British soldiers. The IRA men convinced the soldiers to continue their drinking on a nearby hillside and when they got them drunk enough, executed them. That was the 30th killing event of the Northern Ireland "Troubles."

Why this killing at that moment? Our instinct would be to try to answer that question by looking back in time to find some motive. Maybe the IRA was avenging a previous killing, and if so, the motive for this killing would be revenge. And indeed, on the fifth day of heavy rioting between Catholics and Protestants in North Belfast, a British Army (hereafter, BA) sniper shot James Saunders, a known IRA man, on Old Bank Road. Saunders died because some British soldiers purposefully delayed the arriving ambulance. This murder is potentially linked to the first killing by revenge. If this were the case, the IRA took the opportunity of drinking with soldiers to exact revenge. But why did the British let Saunders bleed to death?

\footnotetext{
'Leiberman Research Worldwide, Los Angeles, CA, USA

${ }^{2}$ Columbia University, New York, NY, USA

\section{Corresponding Author:}

Peter Bearman, Department of Sociology, Columbia University, 6062 I22nd Street, Rm 70I, New York, NY 10027, USA.

Email: psbI7@columbia.edu
} 
Well, six months before the IRA killed the British soldiers on the hillside-and five months before the British soldiers killed James Saunders - two officers of the Royal Ulster Constabulary (RUC) were called to investigate an abandoned Ford Cortina in Armagh. Finding the doors locked, they tried to pry them open, detonating a hidden explosive. The IRA claimed responsibility for this killing. Perhaps James Saunders's death was revenge by the British army for the killing of their allies in the RUC.

The search in the past for a motive for a subsequent event leads to an infinite regress and invites accounts of event sequences that are just-so stories. And yet in periods of large-scale civil conflict, killings result from killings that produce further killing in a long and complex series of causal chains. The argument of this article is that understanding how killings yield subsequent killings is not one that existing strategies for making sense of conflict consider. By focusing on the fact that there are chains of killing that bind violence over time, we develop a method for observing the set of opportunities that groups have to achieve desirable ends (like revenge or domination) by killing. By focusing on the choices (to kill and whom to kill) that they do make from the opportunities that they have, we can infer what groups try to do when they kill members of other groups, as an overall profile. This leads us to a network perspective in which killings are seen as interaction events that tie perpetrators of violence (senders) with victims (receivers), where both perpetrators and victims are organizational groups, such as the IRA and BA.

Civil violence is typically seen as motivated by class, sectarian, and/or ethnic ties (in feelings of injustice or deprivation, religiosity, or ethnic identity) that arise when a conjunction of macro-level factors (state breakdown, social change, economic collapse, etc.) rupture extant and underlying cleavages and open abstract "political opportunities" for violence (Chirot and Ragin 1975; Collier, Hoeffler, and Soderbom 2004; Skocpol 1979). The approach we develop here differs from the extant literature in three ways. First, rather than focus on conflict onset, we focus on the one fact that large-scale civil conflicts share: that they involve one killing after another over very long periods. Second, we focus on killing events and their temporal ordering rather than rates. When one focuses on rates, the specific order in which events occur is lost. Finally, we seek an explanation of conflict continuity in terms of the linkages that exist between the killing events that compose the conflict. Our goal is to show how the focus on the order of killing and behavior of groups can contribute to explaining why conflicts endure. From this perspective, we identify how purely endogenous dynamics lead to conflict continuity and more unusually, conflict failure, or peace.

The context we explore is the 30-year conflict in Northern Ireland. The length of this conflict is not unusual. Lebanon erupted in conflict in 1975, which then lasted for 15 years. Conflict in Sierra Leone began in 1991 and ended in 2002. In Sri Lanka, civil war started in 1983 and ended in 2009. The Guatemalan conflict endured for 36 years, from 1960 to 1996. These conflicts appear in heterogeneous contexts. In some, deep-seated religious cleavages dominate. In others, ethnic, class, or territorial cleavages appear more salient. In some instances, conflict follows state collapse. It is sociologically striking that across conflicts vastly different in content that the characteristic that they all share is their duration.

The problem with just-so stories - starting with an outcome and making up a causal story by linking events seemingly related to it that happened in the past-is that they do not provide a way for us to see all the other things that groups in the conflict could have done at the same time. To break free of just-so stories, we need to focus on the mechanisms by which killing events produce subsequent killing events. In any complex conflict involving multiple groups, the opportunities for further killing overlap and interweave throughout the duration of conflict. For this reason, the opportunities that groups have to kill can be considered pathways to violence. These pathways are such that a next killing can happen in multiple ways. 


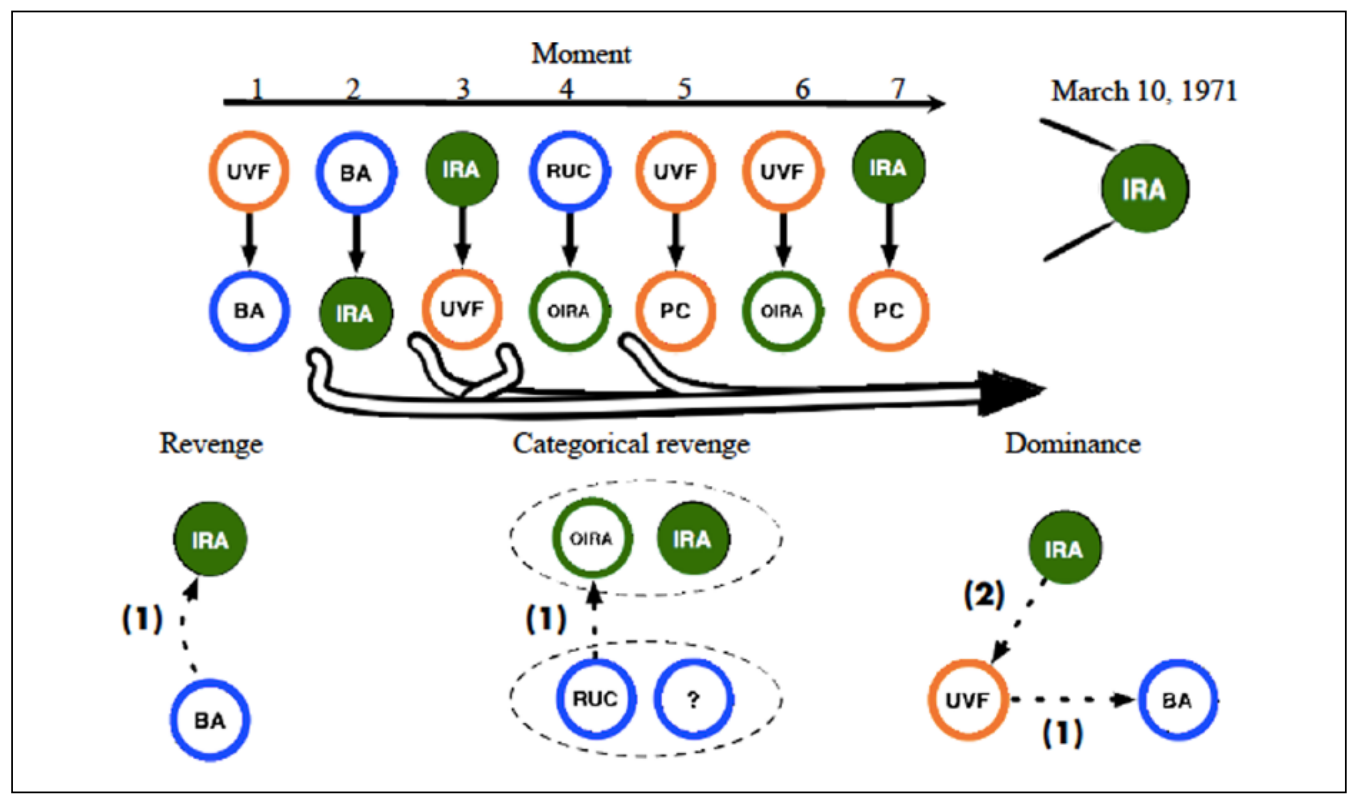

Figure I. The view of the proximate past as a series of killing events providing opportunities to exact/ achieve revenge, categorical revenge, and dominance.

If there are lots of opportunities for a next killing, then the likelihood that there will be a next killing is higher than if there are few such opportunities. It is a truism that violence ends when there is no reason to kill. If, for example, revenge was the motive for killing and no groups had any prior killings to avenge, they would not kill. Our analytical strategy shows that violence ends when there are no more pathways to violence.

\section{Revenge and Domination}

Assume that when groups kill, they are pursuing some interactional motive and that one can capture this motive as a configuration of interaction that arises from their specific past. We start with two of the known motives for killing, revenge and dominance (Gould 2002, 2003; Papachristos 2009). Revenge can be either direct or generalized (categorical). The interaction configurations that these motives arise from are shown in Figure 1. In simple terms, one group may kill another because they want to get back at them (direct revenge), dominate them or some other group, or are friends of a group they want to get back at (categorical or generalized revenge). Direct revenge is commonly thought to be a central motive for killing (Elster 1990; Gould 2002; Kalyvas 2006). The friends of ones' enemies are also enemies, and so revenge may be achieved by killing them. When conflicts assume a categorical shape-Catholic versus Protestant, Bosnian versus Serb - the exercise of generalized revenge would mean that groups frame revenge not at the group level but at the categorical level.

Revenge is easy to represent. Consider group $\mathrm{A}$, one of whose members has been killed by someone in group $\mathrm{B}$. Represent that first killing as $\mathrm{B} \rightarrow \mathrm{A}$. Revenge of the $\mathrm{B} \rightarrow \mathrm{A}$ killing is achieved by $\mathrm{A} \rightarrow \mathrm{B}$. It is more complex for categorical revenge. One configuration of categorical revenge, from the perspective of focal actor $\mathrm{A}$, is $\mathrm{Cx} \rightarrow \mathrm{Ay}, \mathrm{Ay} \rightarrow \mathrm{Bx}$. Here, a focal group, A, of category y (say, Catholic) has a member killed by an actor in Group C, which is 
of category $\mathrm{x}$ (i.e., $\mathrm{Cx} \rightarrow \mathrm{Ay}$ ). Subsequently, A kills a member of group B who is also of category $\mathrm{x}$ instead of directly attacking $\mathrm{C}$. A second configuration of categorical revenge, from the perspective of a focal actor, is $\mathrm{Bx} \rightarrow \mathrm{Cy}, \mathrm{Ay} \rightarrow \mathrm{Bx}$. Here, an actor, $\mathrm{B}$, who is of category $\mathrm{x}$ attacks actor $\mathrm{C}$ who is of category $\mathrm{y}$, which then prompts actor $\mathrm{A}$ who is of category $\mathrm{y}$ to attack actor B. A third configuration of categorical revenge is more diffuse: $\mathrm{Cx} \rightarrow \mathrm{Dy}$, $\mathrm{Ay} \rightarrow \mathrm{Bx}$. Here, if actor $\mathrm{C}$ who is of category $\mathrm{y}$ receives violence from actor $\mathrm{D}$ who is of category $\mathrm{x}$, the focal actor A who is of category $\mathrm{y}$ attacks actor B who is of category $\mathrm{x}$. Such a configuration involves four actors.

Transitivity is the basic configuration for dominance (Chase 1980). A transitivity configuration, from the perspective a focal actor $\mathrm{A}$, appears as: $\mathrm{A} \rightarrow \mathrm{B}, \mathrm{B} \rightarrow \mathrm{C}, \mathrm{A} \rightarrow \mathrm{C}$. Transitivities produced from killing ties produce linear dominance hierarchies. Here, dominance is the achievement of a transitive configuration of killing ties from the perspective of a focal actor. These three configurations - revenge, categorical revenge, and dominance-provide possible motives for killing. They do not exhaust all possible motives, and groups may kill without any of these motives in play. But they do cover the reasons for killing most often described in the literature. Answering the question of which motive predominates for whom is crucial for understanding the dynamics of violence.

\section{CASE AND DATA}

The empirical evidence for this article comes from Northern Ireland. We rely on Sutton's ([1994] 2001) and McKittrick et al.'s (2001) complete inventory of the killings attributable to the 32-year conflict, which include the date and exact location, the group(s) responsible, and the group and/or religious affiliation of decedents to identify all the killings that compose the conflict as it unfolds. The actors in our analysis are the militarized groups, such as the British Army, the Irish Republican Army, and the Ulster Volunteer Force (hereafter, UVF), among others. We define an interaction as a unique and directed killer-victim tie on a particular day at a particular location. We transform deaths of individuals to killing events. From these events, 24 groups were active, to some degree, throughout the Northern Irish conflict. Eighteen of these groups are perpetrators of violence, and 20 are victims. We aggregate less active groups into "Other" groups, doing so by their political identities. Our analysis is based on 10 groups, with 3 of those groups being "Other Loyalist," "Other Republican," and "Other Security." The distribution of killing is very uneven. Three of the groups (the IRA, the UVF, and the BA) account for 72 percent of the events.

\section{ACHIEVEMENT OF OPPORTUNITIES}

One can assume that action is directed toward achieving a desired end, but we cannot assume that just because a killing achieves revenge that it was motivated by revenge. To determine which reason may have been in play, one needs further information. This is because in complex multisided conflicts, a single killing often accomplishes more than one goal. The problem, from an analytical standpoint, is that when killings achieve multiple configurations at the same time, the killing conceals which motive might have been behind it. To illustrate how common the problem is, we consider empirical data. Figure 1 represents eight killings that took place in 1971. Each circle represents a group. In the top row are the perpetrators of killing, who kill the bottom row, the victims. We take one focal killing, an IRA $\rightarrow$ BA killing (though the principle applies to all killings) and one focal group, the IRA (though the principle applies to all groups). The focal killing is the one we started with, the execution of the three soldiers on the hill. From the IRA point of view, right before they walked into the bar, 


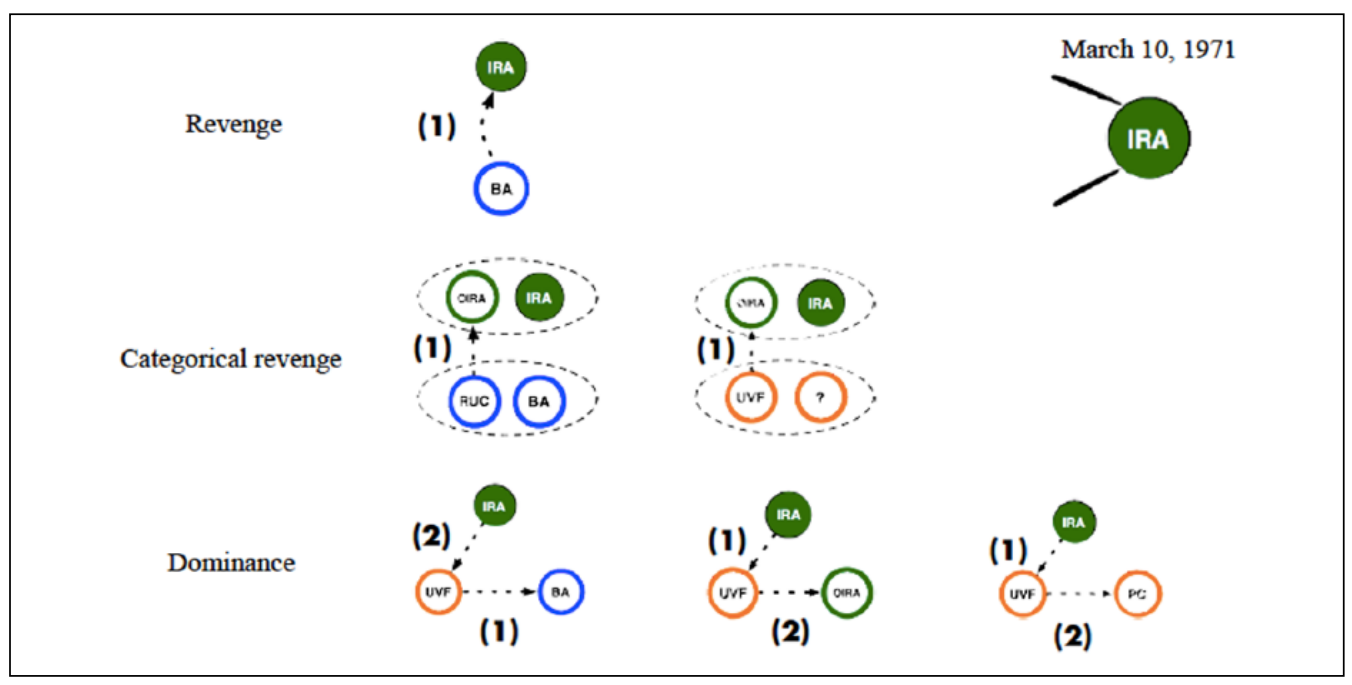

Figure 2. Opportunities for revenge, categorical revenge, and domination taken and missed by the Irish Republican Army at moment (8), March 10, 1971.

from moment (8), we can ask: What events do they see when they look back into their proximate past?

From prior events in their proximate past arise opportunities. The IRA can only see those opportunities relevant to them, in their specific past. One prior opportunity that they see is for dominance, the source of which is from moments (1) and (3), the UVF $\rightarrow$ BA killing linked to the IRA $\rightarrow$ UVF killing. The IRA $\rightarrow$ BA killing could be a dominance killing because it places the IRA at the top of a transitive linear hierarchy: IRA $\rightarrow \mathrm{UVF} \rightarrow \mathrm{BA}$. Complicating matters is that at the same time, the IRA also sees opportunities for revenge and categorical revenge, and by targeting the BA, they achieve those goals - or those configurations - as well. The source of the revenge is from moment (2), when BA $\rightarrow$ IRA. This is the James Saunders killing. The source of the categorical revenge opportunity is from moment (4), when (RUC) kills a member of the $\rightarrow$ Official Irish Republican Army (OIRA). Thus, a killing can achieve multiple configurations at the same time. The opportunities the IRA sees and the outcomes they achieve by the killing at moment (8) are also shown in Figure 1.

It follows that one cannot answer the question of which opportunity any group takes at any moment by looking at an outcome and assembling a story that leads to that outcome because such a strategy results in multiple plausible stories without any guidance as to how to mediate between them. Yet the fact that any one killing can achieve multiple configurations at the same time reveals a previously elusive empirical reality: At every moment, there are multiple action potentials, only some of which get fulfilled, leaving others unfulfilled. It is straightforward to demonstrate that there is unfulfilled action potential at every moment. We show in Figure 2 that while the IRA achieves a dominance, revenge, and categorical revenge configuration when they act at this moment to kill a member of the BA, they miss other opportunities that they could have achieved had they killed members of other groups. Consider two such opportunities. One dominance opportunity, pieced together from events (3) and (6), could have been achieved had the IRA killed some members of the OIRA. A second dominance opportunity, from events (3) and (5), could have been achieved had the IRA killed some Protestant civilians (PC). By not killing members of the OIRA or PC at moment (8), the IRA misses each of these opportunities. 
For the IRA, the exact same moment in time is composed of multiple opportunitiesand they take advantage of only some of those. Had the IRA not killed at (8) at all, they would have missed the dominance, revenge, and categorical revenge opportunities that they did achieve. This is what happens to the other groups. Every group has some amount of opportunity over every moment of killing. Thus, while we have shown this for the IRA, it is possible to do this for all other groups over all moments. The fact that some opportunities do not get realized does not make them any less real to the actors observing them. Opportunities are the experience of actors with respect to killings in their past. Against this background, the first analytical task is to ascertain all of the opportunities for all of the groups at every moment. Then we can see which opportunities are regularly taken and which are regularly missed.

From the perspective of a group, they can take an opportunity only with killing and so confront three possibilities at any moment: (1) They can kill and achieve an opportunity, (2) they can kill but miss an opportunity, and (3) they can miss an opportunity. The opportunities that groups regularly take are their motives for killing. Groups that never take dominance opportunities but always take revenge opportunities, for example, would be characterized as actors who pursue revenge, not dominance. By knowing both the opportunities that are taken and the opportunities that are missed, one can construct the probability that an opportunity leads to killing measured over all moments of interaction. Formalizing how one can ascertain all of the opportunities for all of the actors prior to every moment of interaction requires identifying the relevant past from which network objects arise. We need a strategy of analysis to identify the entire set of opportunities observed by every group prior to every killingboth the opportunities that get taken as well as the opportunities that are missed. It is important to realize that each group has different opportunities: Their pasts differ. There is no single view of the past.

\section{OPPORTUNITIES TAKEN AND MISSED}

At every moment in time, every actor will have some amount of opportunity prior to every next interaction. Every moment in time can be described by a temporal distribution of opportunity for every actor. These distributions are shown in Figure 3, where the solid line represents dominance opportunities, the dotted line revenge opportunities, and the dot-dashed line categorical revenge opportunities. The y-axes across the different types of opportunities and for each group are all the same, which reveals the heterogeneity of opportunity between groups in the shape of the distribution over the duration of conflict as a whole.

From Figure 3, we observe that groups differ in their average amounts of opportunity over the duration of conflict. The IRA, for example, has more opportunities of any given type than does the UDA, and on average, the UDA has more opportunities than does the INLA. But a group's average amount of opportunity has no relationship with their level of perpetration. For example, the UVF and IRA have similar amounts of opportunity, but the IRA kills more than four times as often. This heterogeneity of opportunity matters only to the degree that groups regularly take one type of opportunity over another. Thus, the fact that the IRA has a high number of dominance opportunities matters for understanding killing only if the IRA regularly pursues dominance, in which case they would regularly have reasons to killwhich they do.

For the IRA and many other groups, the shape of the distributions for dominance, revenge, and categorical revenge are quite similar, rising and falling around the same moments. Other groups have opportunities only at particular moments. The most obvious result revealed from Figure 3 is that at any given moment, multiple groups have some opportunity, the same 


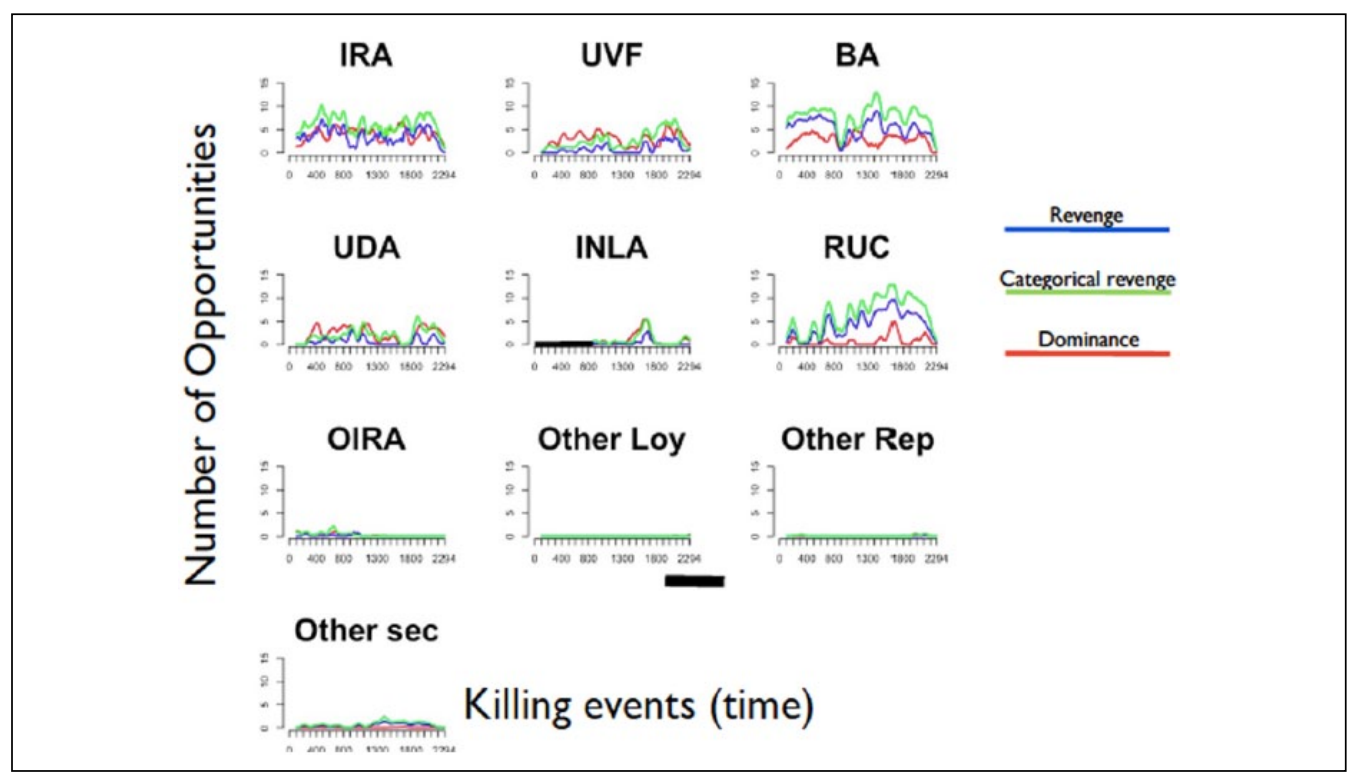

Figure 3. Groups differ on exposure to opportunities.

group has multiple opportunities of any given type, and the same group has multiple types of opportunity.

\section{THE TIMING OF KILLING AND ORIENTATION TO OPPORTUNITIES}

One requires multivariate analysis to mediate between the types of opportunities that groups take with the timing of their killing, which will allow one to discern the partial relationship between opportunity and killing. The multivariate model is a logistic equation, as follows:

$$
y_{g t}=_{g}+{ }_{1} * D O M_{g t}+{ }_{2} * R E V_{g t}+{ }_{3} * C A T R E V_{g t},
$$

where $\alpha$ is the group-level intercept, $D O M$ is the number of dominance (or transitive) opportunities that group $g$ has at moment $m, R E V$ is the number of revenge (or reciprocity) opportunities that group $g$ has at moment $m$, and $C A T R E V$ is the number of categorical revenge opportunities that group $g$ has at moment $m$. The model is specified separately for each group.

The basic intuition is that if groups regularly take a particular type of opportunity, then groups should be more likely to kill when they have more opportunities of that type than expected by chance alone. We use a permutation test to derive an exact distribution of the logistic parameter across the three opportunity types. Killings are temporally ordered, and so their permutation would preserve how much groups kill but would randomly shuffle when they kill. The multivariate logistic parameter is calculated with each randomized permutation of the moments in which groups kill. We preserve the observed temporal distributions of opportunity and therefore the number of opportunities that groups actually observe prior to every moment of killing.

Figure 4 reports the results from this procedure. The rows are groups, and columns are the three types of opportunity. Each row is a separate equation for each group. Each cell is the distribution of the logistic parameter produced from 1,000 random permutations of the 


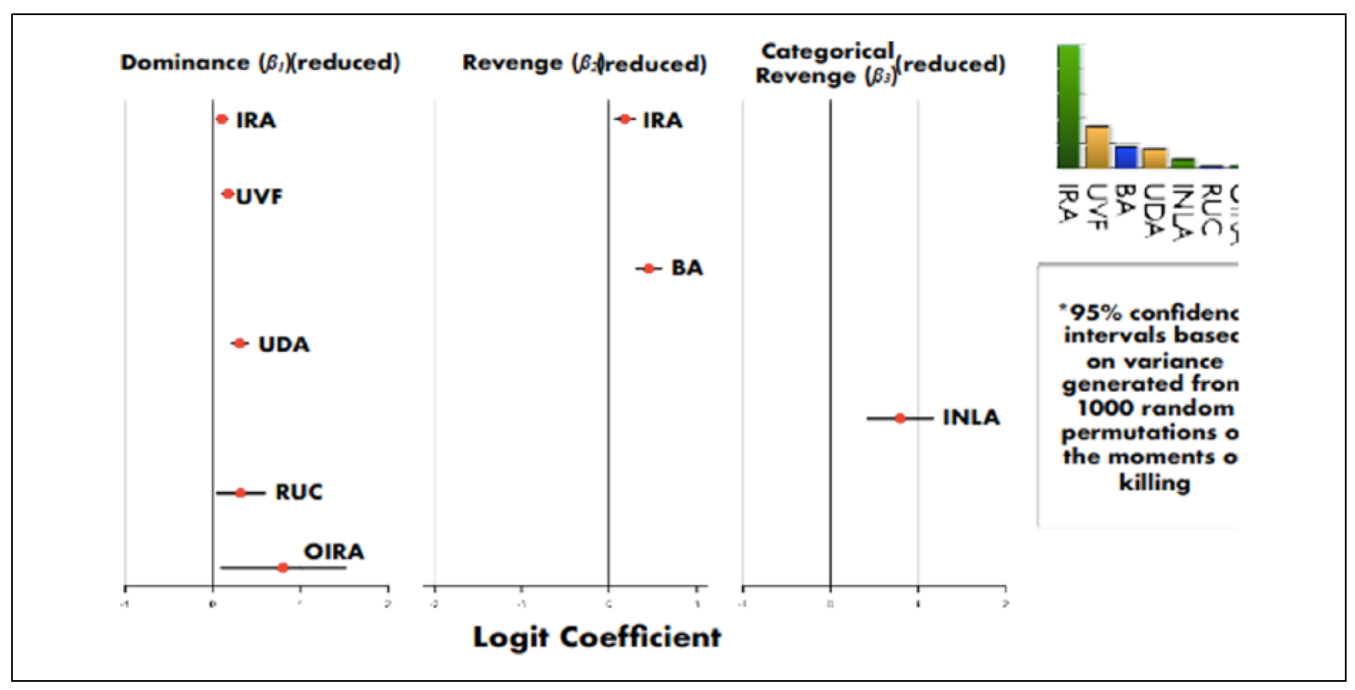

Figure 4. Expressing more motives leads to more killing.

moments in which groups kill. The symbols imposed on the distributions show the observed parameter located on the distribution obtained from repeated random permutations. The diamonds are greater than two standard deviations above the mean.

Figure 4 suggests how killings produce subsequent killings. There are four things to note. First, there are more groups who kill when they have dominance opportunities than groups who kill when they have opportunities for revenge. Second, two groups, the IRA and the BA, regularly kill when they have revenge opportunities. Third, only the timing of killing by the IRA is related to two types of opportunity. Fourth, only the INLA regularly engages in killing only when they have categorical revenge opportunities. Figure 4 also identifies which opportunities are not pursued. The IRA does not kill when they have categorical revenge opportunities, and the BA does not kill when they have dominance opportunities. Perhaps the most critical issue is what groups do when they don't have a motive to kill. The simple answer is that none of them kill.

\section{WHY GROUPS KILL WHO THEY KILL WHEN THEY KILL}

Having addressed the problem of why groups kill when they kill, we now turn to why groups kill who they kill when they kill. This question of targeting can be answered by trying to understand more directly how regularly groups take an opportunity and so achieve a particular outcome. The taking of an opportunity involves achieving a configuration for which one has an opportunity.

If groups kill at a particular moment to achieve some outcome, they should target other groups with whom they have that opportunity-and so achieve that outcome frequently. There is heterogeneity with respect to the proportion of times that groups achieve the various configuration outcomes they may desire when they have at least one opportunity. This heterogeneity may reflect an important exogenous factor-resources. The IRA, for example, achieves a dominance configuration 31 percent of the time when they have at least one opportunity to do so, compared with 19 percent for the UVF. This aside, our goal, in general, is to ascertain which opportunities, if any, lead to killing. This requires us to make statistical 


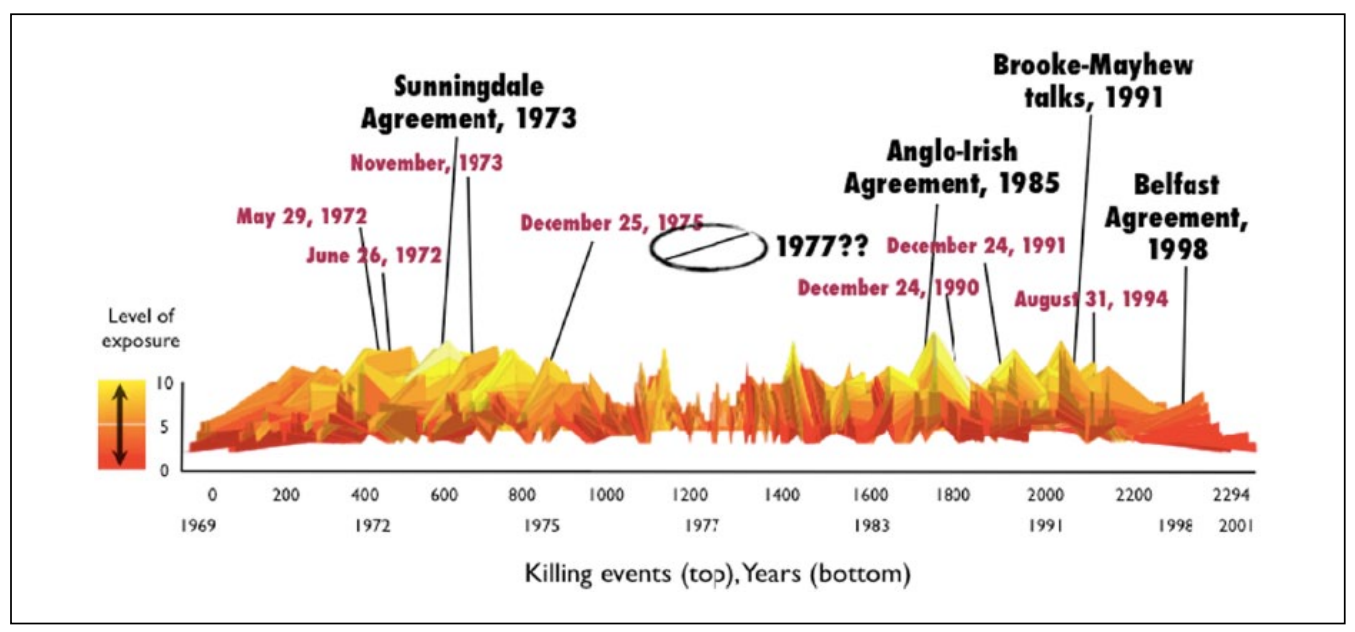

Figure 5. Ceasefires and peace talks take place when opportunities are numerous.

inference around parameter estimates and pay particular attention to the eight candidate motives, as identified from the results in Figure 4. From Figure 4, we observe that only eight of the opportunities are taken with any regularity: The IRA takes dominance and revenge opportunities; the British Army takes revenge opportunities; the UVF, RUC, and OIRA take only dominance opportunities; and the INLA takes only categorical revenge opportunities. By pursuing two types of opportunity, the IRA almost always has a reason to act.

\section{THE CONTINUATION OF KILLING}

Now that we have identified which opportunities lead to killing, we are in a position to answer why the Northern Ireland conflict continued for so long. There are eight principle group-specific motives that undergird group violence. In Figure 5, we report their simultaneous temporal distribution in three dimensions. The $\mathrm{x}$-axis is over the duration of conflict, the $y$-axis is the number of opportunities for the given type, and the z-axis identifies the five types of opportunity that are systematically pursued by these groups. As Figure 5 reports, historical moments are variably fecund with respect to the number of unique opportunities for achieving a goal that they provide. Periods with few opportunities are blighted in the sense that groups have fewer ways to achieve dominance or exact revenge. But when a moment is more fecund, its continuation is less problematic than when it is more barren, when continuation is at greater risk of failure. As shown in Figure 5, the conflict in Northern Ireland continues during moments where there are multiple pathways to violence. In fecund moments, the inaction of one actor can be met by killing by another. In contrast, violence is more likely to end when there are very few pathways to violence, there are very few opportunities, and groups no longer have as many reasons to kill as they did before. Ironically, peace talks and ceasefires happen when people have the greatest motivation to react to the intensity of violence and convince the main participants to sit down and talk. That motivation peaks with opportunities. Is it any wonder, then, why peace talks fail? There are just too many opportunities to take. Instead, conflict ends when, as is evident, there are no more reasons to kill. One can observe missed opportunities for peace in Northern Ireland, specifically in late 1977, when opportunities were few. 


\section{CONCLUSION}

In this article, we focus directly on events to identify the potential endogenous mechanisms of killing. By showing how killings become related in unfolding but smaller scale intertwined group-specific histories, our approach allows us to see how violence gets tied to subsequent violence and therefore how hard it is to break out of a cycle of killing. Current conflicts raging in various parts of the world provide an unsettling reminder that civil violence continues over long durations. That is because in multisided conflicts, many groups have reasons to kill, reasons provided to them as opportunities to achieve coveted ends such as revenge or dominance. An important irony, visible from Figure 5, is that peace efforts occur when the intensity of conflict increases and hence when opportunities to kill abound. It is no wonder they fail. A second irony is that it is "peacekeepers" like the BA who propel conflict forward. In the Northern Ireland case, peace becomes possible when the number of actors decreases. Most critical in this regard was the departure of the BA.

Of course, anyone recommending that peacekeepers depart from conflict zones because what peacekeepers actually do is sustain killing has to believe ending conflict is an ultimate ideal. And that is not so obvious. The conflict in Sri Lanka ended because the government drove the Tamil Tigers to the sea and slaughtered all of them.

\section{ACKNOWLEDGMENTS}

We have benefitted from the comments of Rogers Brubaker, Emily Erikson, David Gibson, Anand Gopal, Peter Hedstrom, Mark Hoffman, B.K. Lee, Debra Minkoff, Andrew Papachristos, Alix Rule, Kate Stovel, Harrison White, Josh Whitford, and Andreas Wimmer. Emily Erikson helped get this version down from $\sim 14,000$ words to $\sim 4,500$ words.

\section{FUNDING}

The author(s) disclosed receipt of the following financial support for the research, authorship, and/or publication of this article: Support for this project arises from the Interdisciplinary Center for Innovative Theory and Empirics (INCITE), the Andrew Mellon Foundation, and the NIH Director's Pioneer Award program, part of the NIH Roadmap for Medical Research, through grant number 1 DP1 OD003635-01.

\section{REFERENCES}

Chase, Ivan D. 1980. "Social Process and Hierarchy Formation in Small Groups: A Comparative Perspective." American Sociological Review 45(6):905-24.

Chirot, Daniel, and Charles Ragin. 1975. "The Market, Tradition and Peasant Rebellion: The Case of Romania in 1907." American Sociological Review 40(4):428-44.

Collier, Paul, Anke Hoeffler, and Mans Soderbom. 2004. "On the Duration of Civil War." Journal of Peace Research 41(3):253-73.

Elster, Jon. 1990. "Norms of Revenge." Ethics 100(4):862-85.

Gould, Roger V. 2002. "The Origins of Status Hierarchies: A Formal Theory and Empirical Test." American Journal of Sociology 107(5):1143-78.

Gould, Roger V. 2003. Collision of Wills: How Ambiguity about Social Rank Breeds Conflict. Chicago: University of Chicago Press.

Kalyvas, Stathis N. 2006. The Logic of Violence in Civil War. Cambridge, UK: Cambridge University Press. McKittrick, David, Brian Feeney, Chris Thornton, David McVea, and Seamus Kelters. 2001. Lost Lives: The Stories of the Men, Women and Children Who Died through the Northern Ireland Troubles. Edinburgh, UK: Mainstream.

Papachristos, Andrew V. 2009. "Murder by Structure: Dominance Relations and the Social Structure of Gang Homicide." American Journal of Sociology 115(1):74-128.

Skocpol, Theda. 1979. States and Social Revolutions: A Comparative Analysis of France, Russia, and China. Cambridge, UK: Cambridge University Press. 
Sutton, David. [1994] 2001. Bear in Mind These Dead: An Index of Deaths from the Conflict in Northern Ireland: 1969-1993. Belfast: Beyond the Pale Publications.

\section{AUTHOR BIOGRAPHIES}

Hrag Balian is director of marketing science at LRW, a market research firm, in Los Angeles. His interests center on micro-processes, with his current work focused on finding commercial applications to sociological frameworks and methods.

Peter Bearman is the Cole Professor of Social Science at Columbia University. His new work focuses on identifying the neural signatures of social relations and the semantic structure of large text corpora. In addition, most recently, with Adam Reich he is the author of Working for Respect: Community and Conflict at Walmart (Columbia University Press, June 2018). 